\title{
Nur77 Contributes to the Pathogenesis of Pulmonary Edema
}

\author{
Yinkai $\mathrm{Ni}^{1 *}$, Gengming $\mathrm{Niu}^{2 *}$, Jinlong $\mathrm{Zhao}^{1}$, Liang $\mathrm{Fu}^{1}$ and $\mathrm{Feng} \mathrm{Li}^{1}$ \\ ${ }^{1}$ Cardiovascular Surgery Department, Shanghai Jiao Tong University Affiliated Sixth People's Hospital, China \\ ${ }^{2}$ General Surgery Department, Shanghai Fifth People's Hospital, Fudan University, China
}

*Corresponding author: Yinkai Ni, Cardiovascular Surgery Department, Shanghai Jiao Tong University Affiliated Sixth People's

Hospital, China

Gengming Niu, General Surgery Department, Shanghai Fifth People’s Hospital, Fudan University, China

\section{ARTICLE INFO}

Received: 栔 November 28, 2019

Published: 幽 December 06, 2019

Citation: Yinkai Ni, Gengming Niu, Jinlong Zhao, Liang Fu, Feng Li. Nur77 Contributes to the Pathogenesis of Pulmonary Edema. Biomed J Sci \& Tech Res 23(4)-2019. BJSTR. MS.ID.003940.

Keywords: Nur77; Endothelial Cells; Pulmonary Edema

\begin{abstract}
The nuclear receptor Nur77 is actively involved in a variety of pulmonary diseases such as lung cancer, airway inflammation, ARDS and pulmonary artery hypertension. However, it remains unknown whether Nur77 plays a role in the pathogenesis of pulmonary edema. The objective of this study is to identify the relationship between Nur77 and pulmonary edema. By using quantitative real-time PCR (qRT-PCR), immunofluorescent staining and Western Blot, we found that Nur77 expression was markedly upregulated in endothelial cells in response to pulmonary edema. After the injection of SiNur77 endothelial cell edema reduces and restores its former structure. In conclusion, we believe that Nur77 plays a pivotal role in the pathogenesis of pulmonary edema.
\end{abstract}

\section{Introduction}

Pulmonary edema occurs when the safety mechanisms of the lung are overwhelmed by either high transvascular pressure gradients or increased microvascular permeability, which makes a large amount of tissue fluid unable to be absorbed by the pulmonary lymph and pulmonary vein system in a very short period of time. The fluid seeps from the pulmonary capillary, and accumulates in the alveolus, thus causing serious impairment of pulmonary ventilation and ventilation function. Pulmonary edema can cause dyspnea, sitting upright, cyanosis, sweating, and paroxysmal cough and is one of the most common causes for admission to the ICU [1]

Pulmonary microvascular endothelial cells (ECs) are integral to the alveoli-capillary barrier of the lung. The EC barrier integrity is disrupted in pulmonary edema [2]. The EC gaps allow for permeability of fluid, neutrophils and cytokines into the pulmonary parenchymal space [3]. The neutrophils that infiltrate the lungs express pro-inflammatory cytokines such as tumor necrosis factoralpha (TNF- $\alpha$ ), interleukin-1 beta (IL-1 $\beta$ ), and contribute to both the endothelial and epithelial integrity disruption of the barriers $[4,5]$.
The nuclear receptor (NR) superfamily of transcription factors contains 48 members [6]. NR4A receptors are a subset of orphan receptors which include NR4A1 (Nur77, TR3, NGFI-B), NR4A2 (Nurr1) and NR4A3 (NOR-1) [7-10]. Recently, much attention has been paid to the functional role of NR4A receptor in cardiovascular system. In vascular ECs, expression of Nur77 is increased by hypoxia, TNF- $\alpha$, and vascular endothelial growth factor (VEGF) to modulate EC growth, angiogenesis, and inflammation $[11,12]$. However, it remains unclear whether Nur77 is involved in pulmonary edema. In this article, we use both in vitro and in vivo models to explore the potential roles of Nur77 in pulmonary edema.

\section{Materials and Methods}

\section{Mice}

C57BL/6 mice were purchased from Shanghai Slac Laboratory Animal CO.LTD. All experimental protocols conducted on the mice were approved by the Committee for Animal Welfare of the Academic 
Medical Center, Shanghai Jiaotong University and were performed in accordance with the standards established by Chinese government. Intraperitoneal injection of $0.1 \mathrm{ml} / 10 \mathrm{~g}$ adrenaline $(1 \mathrm{mg} / \mathrm{ml})$ was administered to 8 weeks old male mice. Thirty minutes after injection, mice were anesthetized with isoflurane and the lungs were harvested.

\section{Cell Isolation}

Lung tissues were cut to $1 \mathrm{~mm} 3$ and the filtrate was harvested. $5 \mathrm{ul}$ anti-CD31 antibody and 20ul magnetic beads were mixed for 20 minutes at room temperature. Mix the filtrate and the mixture of antibody and beads in a ratio of 1:3 for 2 hours at room temperature. Then pulmonary endothelial cells were harvested.

\section{Quantitative Real Time-PCR (qRT-PCR)}

Total RNA was extracted from lung tissues and pulmonary endothelial cells using Trizol reagent kit (Invitrogen). The RNA concentration was measured using Nano Drop 2000 (Thermo Fisher Scientific, Inc). Then qRT-PCR analysis was performed. Briefly, cDNA was synthesized from total RNA using High Capacity cDNA Archive Kit (Applied Biosystem). qRT-PCR was performed using SYBR Green qRT-PCR Master Mix Kit (AB science). qRT-PCR primers used for amplification of Nur77were: mice Nur77 (forwardprimer:5'-GAGTTCGGCAAGCCTACCAT-3', reverse primer: 5'-GTGTACCCGTCCATGAAGGTG-3'), Cadh5 (forwardprimer:5'-CCACTGCTTTGGGAGCCTT-3', reverse primer: 5'-GGCAGGTAGCATGTTGGGG-3'), Gapdh (forwardprimer:5'AGGTCGGTGTGAACGGATTTG-3', reverse primer: $5^{\prime}$-GGGGTCGTTGATGGCAACA-3').

\section{Immunofluorescent Staining}

Pulmonary endothelial cells were fixed and sequentially incubated with anti-Nur77 polyclonal antibody (Santa Cruz Biotechnology) and fluorescein-5-isothiocyanate (FITC)conjugated donkey anti-rabbit antibody (Invitrogen). Images were visualized using an Olympus IX70 epifluorescence microscope.

\section{Western Blot}

Western blot analyses were performed on protein samples extracted from pulmonaryendothelial cells of C57BL/6 mice injected with PBS or adrenaline. Cell lysates were prepared using RIPA buffer (Thermo Scientific). Pulmonaryendothelial cells were homogenized in ice-cold cell lysis buffer. Protein concentrations were determined by the BCA Protein Assay Kit (Pierce, Rockford, IL, USA). Equal amounts of protein were electrophoresed on an SDSPAGE (10\%) and transferred onto PVDF membranes. Blots were blocked with $5 \%$ nonfat milk in TBST and then developed with diluted antibodies against Nur77 (Abcam) or GAPDH (Santa Cruz Biotechnology)for $2 \mathrm{hr}$ at room temperature and incubated with secondary antibodies(anti-rabbit, Abcam) for $1 \mathrm{hr}$. Immunoreactive products were detected by chemiluminescence with an enhanced chemiluminescence system (GE Healthcare).

\section{Statistical Analyses}

Results are presented as mean \pm SD. Student's $t$ test was employed to determine statistical significance. In all cases, $\mathrm{P}<0.05$ was considered statistically significant.

\section{Results}

\section{Experimental Protocol and Establishment of Mice Pulmonary Edema Models}

To define the role of Nur77 in the pathogenesis of pulmonary edema, we first set up mice pulmonary edema models with C57BL/6 mice by intraperitoneal injection of adrenaline. The control group C57BL/6 mice received the same dosage of PBS. As a result, the weight and length of right lungs in adrenaline group are significantly increased compared with the control group. Lung sections of mice models stained with H\&E show obvious edema and abscission occurring in endothelial cells in adrenaline group (Figure 1).

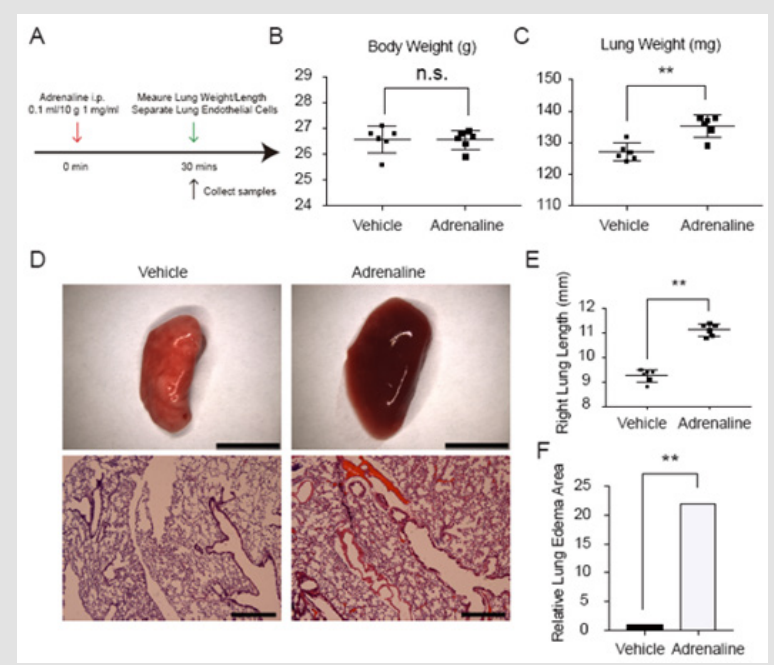

Figure 1: Mice pulmonary edema models were established by intraperitoneal injection of adrenaline. 
Total Lung Nur77 Increased in Pulmonary Edema Models

The expression of NR4A1 gene increased under the condition of hypoxia (Figure 2A). Total lung Nur77 increased in pulmonary edema models compared with control (Figure $2 \mathrm{~B}$ ). ${ }^{* *} \mathrm{P}<0.01$.

\section{Purification of Pulmonary Endothelial Cells}

Specific marker of vascular endothelial cells Cdh5 was quantified by qRT-PCR. Pulmonary endothelial cells were stained by Immunofluorescent staining (VE-Cadherin/Dapi). Purified vascular endothelial cells were obtained by methods mentioned above (Figure 3 ). ${ }^{* *} \mathrm{P}<0.01$.
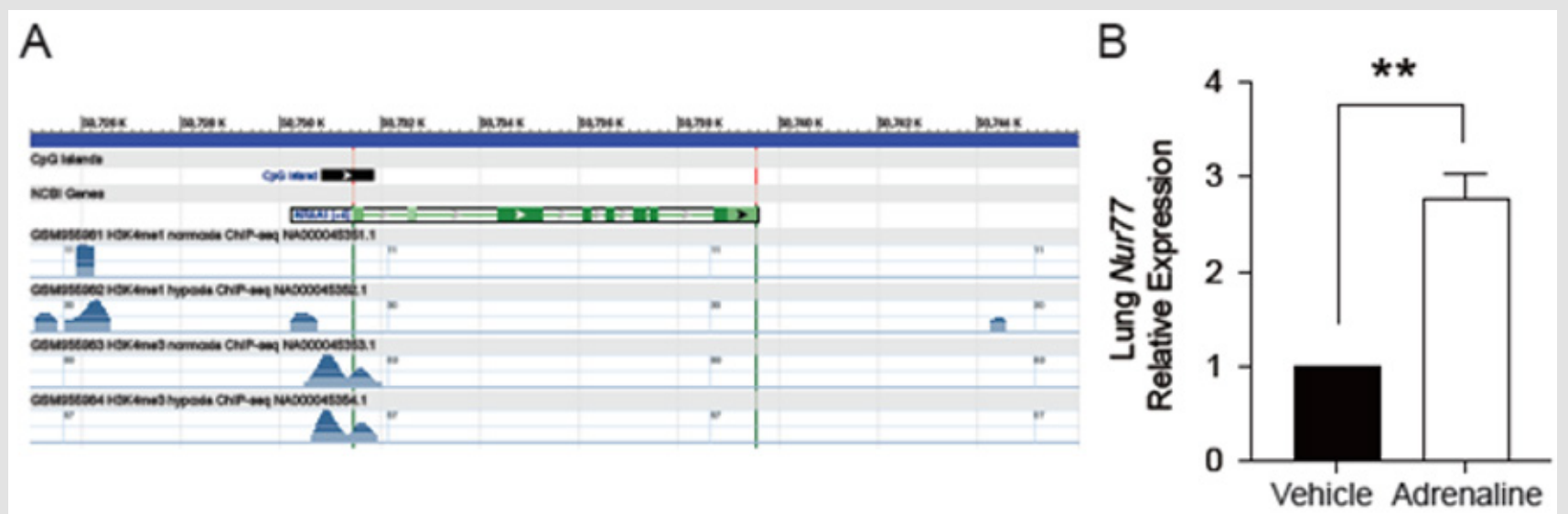

Figure 2:

A. The expression of NR4A1 gene increased under the condition of hypoxia.

B. Total lung Nur77 increased in pulmonary edema models compared with control.
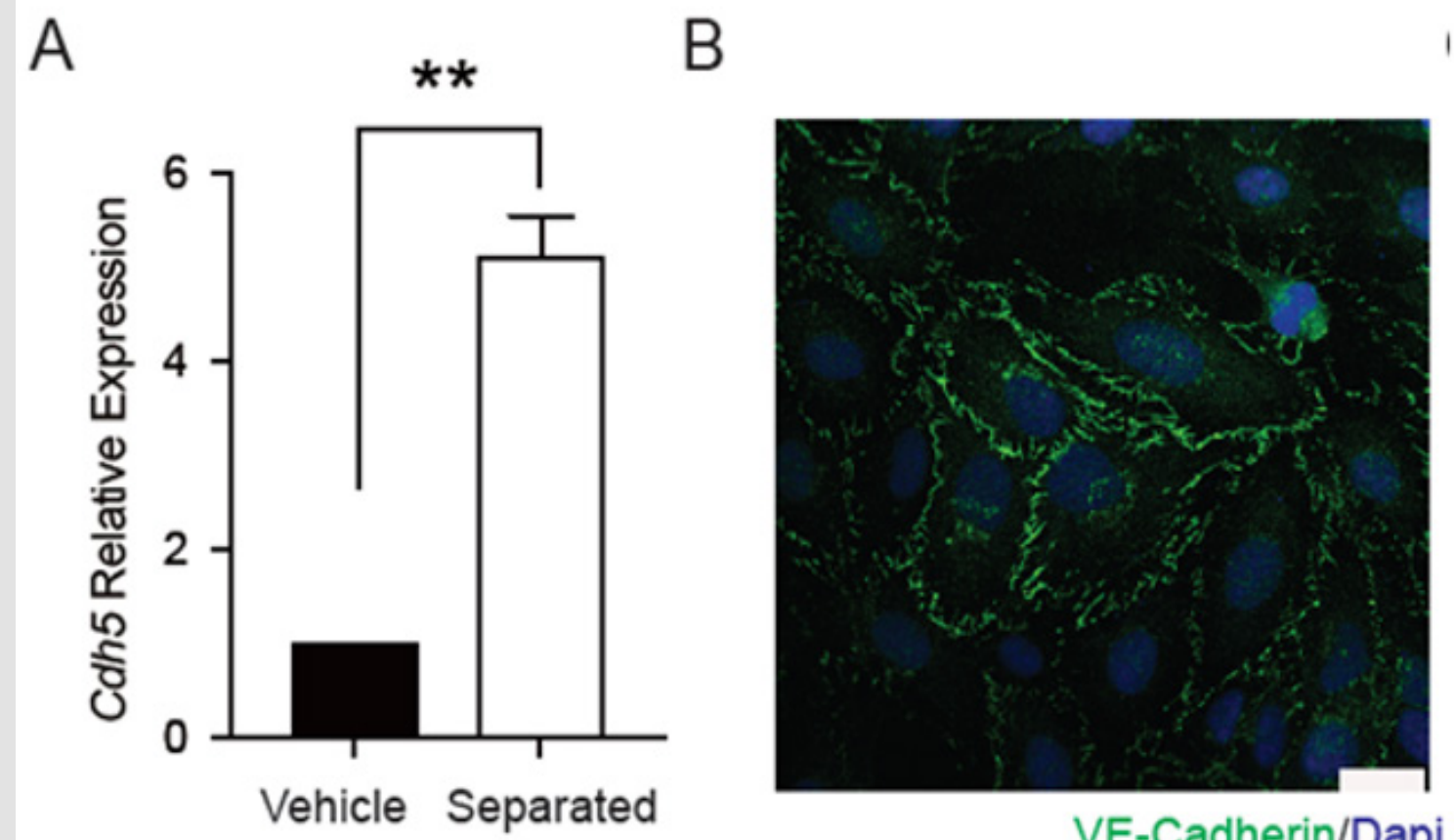

\section{VE-Cadherin/Dapi}

Figure 3: Purified vascular endothelial cells were obtained by methods.

\section{Nur77 Increased in Edematous Pulmonary Endothelial} Cells

We sought to explorethe impact of Nur77 on edematous pulmonary endothelial cells. Edematous pulmonary endothelial cells were harvested. Western Blot and qRT-PCR were performed. As expected, Nur77 increased in edematous pulmonary endothelial cells (Figure 4). ${ }^{* *} \mathrm{P}<0.01$. 

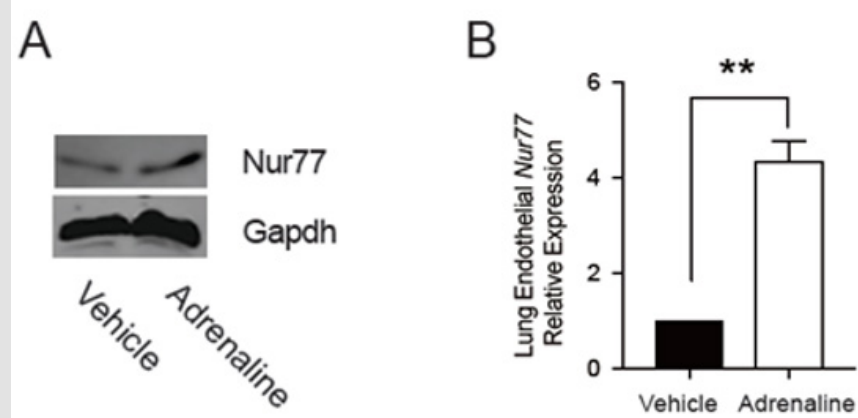

Figure 4: Nur77 increased in edematous pulmonary endothelial cells.

\section{Endothelial Edema Decreased After the Injection of SiNur77}

After intraperitoneal injection of adrenaline in C57BL/6 mice, SiNur77 was injected via tail vein of mice immediately. After 30 minutes, we harvested the lungs and pulmonary endothelial cells. Western Blot and qRT-PCR for Nur77and VE-Cadherin were performed. Nur77 decreased while VE-Cadherin increased in edematous pulmonary endothelial cells in SiNur77 and adrenaline group compared with adrenaline group. H\&E staining of lung sections showed that edema and abscission decreased in SiNur77 and adrenaline group compared with adrenaline group. The structure of endothelial cells was close to control group (Figure 5). ${ }^{*} \mathrm{P}<0.05,{ }^{* *} \mathrm{P}<0.01$.
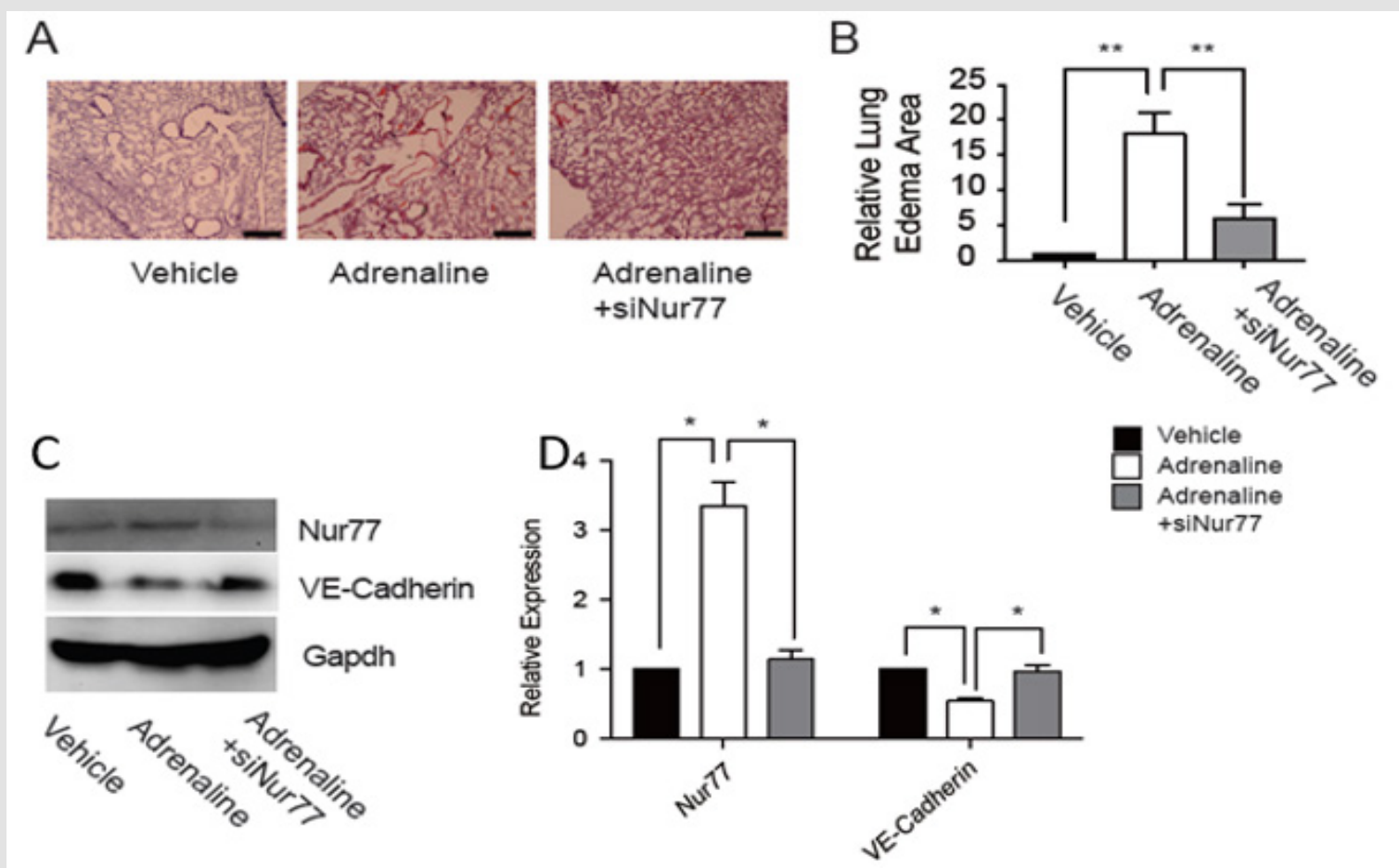

Figure 5: The structure of endothelial cells was close to control group.

\section{Discussion}

Pulmonary edema is caused by the disruption of the pulmonary endothelial barrier [13]. The incidence of pulmonary edema is high and the prognosis is poor. Pulmonary edema can lead to severe hypoxemia. Nur77 is induced in vascular ECs by several stimuli, such as hypoxia, TNF- $\alpha$, and VEGF, and modulate EC growth, survival, and angiogenesis [11,12]. This is consistent with our research. Nur77 expression was markedly upregulated in endothelial cells in response to pulmonary edema. Vascular endothelial growth factor (VEGF) is reported to have profound effects by regulating the epithelial-endothelial barrier, vascular permeability, and inflammatory cytokines [14]. Elevated VEGF levels may be associated with pulmonary inflammation and edema [15]. In ECs exposed to VEGF, Nur77 is one of the most robustly upregulated genes [16]. VEGF-mediated upregulation of Nur77 is mediated through activation of the PKD/HDAC7/MEF2 pathway $[17,18]$. This suggests that Nur77 may damage the endothelial cell barrier and cause pulmonary edema by regulating VEFG.

In summary, Nur77 has emerged as an important regulator of inflammation in various diseases. However, its role in the pathogenesis of pulmonary edema is largely unknown. In this study, we document that Nur77 expression was markedly upregulated in endothelial cells in response to pulmonary edema. This is consistent with the theory that pulmonary edema is caused by the disruption of the integrity of ECs [4,5]. And after the injection of SiNur77, the edema and abscission of decreased EC decreased. However, it remains unclear which signal pathway does Nur77 work through and which cytokines have changed in pulmonary edema. These 
questions require further study. In summary, the data reported herein suggests that Nur77 plays a pivotal role in the pathogenesis of pulmonary edema.

\section{References}

1. O'Brodovich H (2001) Pulmonary edema fluid movement within the lung. Am J Physiol Lung Cell Mol Physiol 281(6): 1324-1326.

2. Kovacs Kàsa A, Varn MN, Verin AD, Gonzales JN (2017) Method for the Culture of Mouse Pulmonary Microvascular Endothelial Cells. Sci Pages Pulmonol 1(1): 7-18.

3. Grommes J, Soehnlein O (2011) Contribution of neutrophils to acute lung injury. Mol Med 17(3-4): 293-307.

4. Bdeir K, Higazi AA, Kulikovskaya I, Christofidou Solomidou M, Vinogradov SA, et al. (2010) Neutrophil alpha-defensins cause lung injury by disrupting the capillary-epithelial barrier. Am J Respir Crit Care Med 181(9): 935-946.

5. Abraham E (2003) Neutrophils and acute lung injury. Crit Care Med 31(4 Suppl): S195-S199.

6. Gronemeyer H, Gustafsson JA, Laudet V (2004) Principles for modulation of the nuclear receptor superfamily. Nat Rev Drug Discov 3(11): 950964.

7. Shi Y (2007) Orphan nuclear receptors in drug discovery. Drug Discov Today 12(11-12): 440-445.

8. Paulsen RF, Granas K, Johnsen H, Rolseth V, Sterri S (1995) Three related brain nuclear receptors, NGFI-B, Nurr1 and NOR-1, as transcriptional activators. J Mol Neurosci 6(4): 249-255.

9. Murphy EP, Dobson AD, Keller C, Conneely OM (1996) Differential regulation of transcription by the NURR1/NUR77 subfamily of nuclear transcription factors. Gene Expr 5(3): 169-179.

\section{ISSN: 2574-1241}

DOI: 10.26717/BJSTR.2019.23.003940

Yinkai Ni, Gengming Niu. Biomed J Sci \& Tech Res

cC) This work is licensed under Creative

Submission Link: https://biomedres.us/submit-manuscript.php
10. Saucedo Cardenas O, Kardon R, Ediger TR, Lydon JP, Conneely OM (1997) Cloning and structural organization of the gene encoding the murine nuclear receptor transcription factor, NURR1. Gene 187(1): 135-139.

11. Zeng H, Qin L, Zhao D, Tan X, Manseau EJ, et al. (2006) Orphan nuclear receptor TR3/Nur77 regulates VEGF-A-induced angiogenesis through its transcriptional activity. J Exp Med 203(3): 719-729.

12. You B, Jiang YY, Chen S, Yan G, Sun J (2009) The orphan nuclear receptorNur77 suppresses endothelial cell activation through induction of IkappaBalpha expression. Circ Res 104(6): 742-749.

13. Ware LB, Matthay MA (2005) Clinical practice. Acute pulmonary edema. N Engl J Med 353(26): 2788-2796.

14. Kaner RJ, Ladetto JV, Singh R, Fukuda N, Matthay MA, et al. (2000) Lung overexpression of the vascular endothelial growth factor gene induces pulmonary edema. Am J Respir Cell Mol Biol 22(6): 657-664.

15. Lan CC, Peng CK, Tang SE, Wu SY, Huang KL, et al. (2016) Anti-Vascular Endothelial Growth Factor Antibody Suppresses ERK and NF- $\kappa B$ Activation in Ischemia-Reperfusion Lung Injury. PLOS ONE 11(8): e0159922.

16. Liu D, Jia H, Holmes DI, Stannard A, Zachary I (2003) Vascular endothelial growth factor-regulatedgene expression in endothelial cells: KDRmediated induction of Egr3 and the related nuclearreceptors Nur77, Nurr1 and Nor1. Arterioscler Thromb Vasc Biol 23(11): 2002-2007.

17. Wang S, Li X, Parra M, Verdin E, Bassel Duby R, et al. (2008) Control of endothelial cellproliferation and migration by VEGF signaling to histone deacetylase 7. Proc Natl Acad Sci USA 105(22): 7738-7743.

18. Ha CH, Jhun BS, Kao HY, Jin ZG (2008) VEGF stimulates HDAC7 phosphorylation and cytoplasmic accumulation modulating matrix metalloproteinase expression and angiogenesis. Arterioscler Thromb Vasc Biol 28(10): 1782-1788.

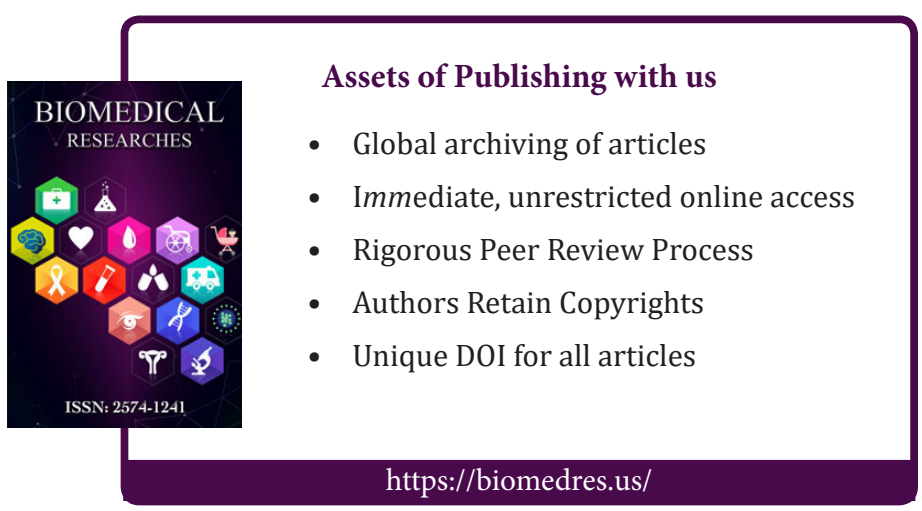

